\title{
BMJ Open Spending on social and public health services and its association with homicide in the USA: an ecological study
}

\author{
Heather L Sipsma, ${ }^{1,2}$ Maureen E Canavan, ${ }^{1}$ Erika Rogan, ${ }^{1}$ Lauren A Taylor, ${ }^{3}$ \\ Kristina M Talbert-Slagle, ${ }^{1}$ Elizabeth $\mathrm{H}$ Bradley ${ }^{4}$
}

To cite: Sipsma HL, Canavan ME, Rogan E, et al. Spending on social and public health services and its association with homicide in the USA: an ecological study. BMJ Open 2017;7:e016379. doi:10.1136/ bmjopen-2017-016379

- Prepublication history for this paper is available online. To view these files please visit the journal online (http://dx.doi. org/10.1136/bmjopen-2017016379).

Received 21 February 2017 Revised 25 August 2017 Accepted 29 August 2017

\section{CrossMark}

${ }^{1}$ Department of Health Policy and Management, Yale School of Public Health, New Haven, Connecticut, USA

${ }^{2}$ Department of Public Health, Benedictine University, Lisle, IL, USA

${ }^{3}$ Harvard Business School, Boston, Massachusetts, USA

${ }^{4}$ Vassar College, Poughkeepsie, New York, USA

Correspondence to Dr Elizabeth H Bradley; ebradley@vassar.edu

\section{ABSTRACT}

Objective To examine whether state-level spending on social and public health services is associated with lower rates of homicide in the USA.

Design Ecological study.

Setting USA.

Participants All states in the USA and the District of Columbia for which data were available $(n=42)$.

Primary outcome measure Homicide rates for each state were abstracted from the US Department of Justice Federal Bureau of Investigation's Uniform Crime Reporting. Results After adjusting for potential confounding variables, we found that every $\$ 10000$ increase in spending per person living in poverty was associated with 0.87 fewer homicides per 100000 population or approximately a $16 \%$ decrease in the average homicide rate (estimate $=-0.87, \mathrm{SE}=0.15, \mathrm{p}<0.001$ ). Furthermore, there was no significant effect in the quartile of states with the highest percentages of individuals living in poverty but significant effects in the quartiles of states with lower percentages of individuals living in poverty.

Conclusions Based on our findings, spending on social and public health services is associated with significantly lower homicide rates at the state level. Although we cannot infer causality from this research, such spending may provide promising avenues for homicide reduction in the USA, particularly among states with lower levels of poverty.

\section{BACKGROUND}

Although homicide rates in the USA are substantially lower today than they were at their peak in 1980, they have shown little decline since the year 2000. ${ }^{1}$ More than 16000 homicides occurred in the USA during $2013^{2}$ at an annual estimated cost of more than $\$ 25$ billion, including costs due to both medical care and lost productivity. ${ }^{3}$ Costs may be more than 10 times higher after accounting for other direct costs, including those associated with police investigations, prosecution and imprisonment, as well as indirect costs, such as those associated with economic losses to employers, community trauma and

\section{Strengths and limitations of this study}

- Our study expands the current literature by examining state-level spending effects on homicide rates across the USA

- This analysis was limited to data from the years 2005 to 2009, and thus lacks the ability to examine longer term effects and may lack generalisability to more current homicide rates.

- We cannot infer causality with these data, despite using lagged effects.

- We lacked complete data on potentially important confounders, such as percentage of firearm owners.

- We were unable to determine the independent effects of each service (eg, housing and education) on homicide rates.

migration out of neighbourhoods prone to high rates of violence. ${ }^{4}$ People moving from and avoiding high-crime areas weakens local economies, lowers home values, lowers the tax base and ultimately limits capacity to offer quality public schools and needed social services. Additionally, indirect costs of homicide can include mental healthcare and lost productivity for close friends or family of the victim. Survivors are at increased risk for post-traumatic stress disorder, depression and/or prolonged grief disorder. ${ }^{5}$ Despite efforts throughout the country to reduce homicide, the homicide rate in the USA is seven times higher than other high-income countries. $^{6}$

Much research has examined the influence of individual-level factors and structural-level factors, such as those pertaining to the social, economic and physical environment, on homicide. Specifically, studies suggest that homicide disproportionately affects young adults ages 15-24 years, males and non-Hispanic black individuals. ${ }^{7-10}$ Additionally, communities with high minority populations, 
high unemployment rates and high poverty also tend to have higher homicide rates. ${ }^{11-16}$ Increased violence has also been associated with lower levels of social capital and increased income inequality. ${ }^{17-19}$ Furthermore, more restrictive state-level legislation concerning firearms, such as stronger background checks and bans on military-style assault weapons, are associated with less firearm-related violence, including both suicide and homicide. ${ }^{1516} \mathrm{Homi}-$ cide rates also appear to be associated with public housing policies, ${ }^{20}$ early education programmes ${ }^{121}$ and environmental neighbourhood features. ${ }^{22}$ Together, these findings suggest connections between social determinants of health and violence, as well as the potential influence of state-level policies on violence.

Recent studies suggest that state-level spending on social and public health services may lead to improvements in a variety of health outcomes, including HIV/AIDS, acute myocardial infarction (AMI)mortality and obesity, ${ }^{23} 24$ but limited recent research has examined its effect on homicide in the USA. Several studies have suggested that greater assistance to the poor is associated with lower homicide rates in the USA ${ }^{25-29}$ but much of this research was conducted more than 15 years ago. ${ }^{26-31}$ Given that patterns of contemporary homicide rates in the USA are meaningfully different from those in the 1990s, additional analyses of this relationship are warranted. ${ }^{1}$ Furthermore, although findings from recent cross-national studies have suggested a significant relationship between welfare support and homicide exists, ${ }^{32} 33$ another cross-national study found no association between public expenditures, defined as government investment in health and education, and homicide. ${ }^{17}$ Thus, additional research on this association of social and public health service spending is needed.

Accordingly, we sought to examine the association between rates of homicide and state-level spending on social and public health services from the previous year, such as investments in housing, education and income support. We hypothesised that this spending may result in better quality school systems and thus better educational and economic opportunities for individuals. ${ }^{345}$ Spending on housing may translate into improved residential stability and thus less family disruption and greater social capital. ${ }^{36}{ }^{37}$ Spending on the environment and on public safety may result in more safe spaces for recreation and less space for illegal activities. This spending may provide needy individuals with financial assistance, potentially improving health and development; ${ }^{38} 39$ spending on transportation services may improve mobility within and between communities and opportunities; and spending on community healthcare programmes may result in improved access to healthcare and services. ${ }^{40}$ We hypothesised these investments may have an important beneficial effect on homicide rates. We also explored whether the relationship between spending and homicide rates varied by percentages of individuals living in poverty. Because ultimately we could not adjust for poverty directly in our multivariable model due to issues with multicollinearity, we sought to disentangle these effects by testing for effect modification. We hypothesised that these associations would be stronger within areas of high poverty than in areas of low poverty, since increases in spending in areas with fewer resources could be more impactful than the same increases in areas with more resources. Thus, we used the most contemporary data available from the National Health Expenditures Data (based on the Centers for Medicare \& Medicaid data) and social and public health services spending data from the US Census Bureau. We gathered crime statistics from the US Department of Justice Federal Bureau of Investigation's Uniform Crime Reporting (UCR). Findings from this state-level analysis may encourage robust social and public health spending efforts among policymakers to reduce violence in the USA.

\section{METHODS}

\section{Study design}

We conducted an ecological study over 5 years by constructing a dataset that included spending on healthcare services, public health services and social services among the 50 states in the USA and the District of Columbia. ${ }^{23}$ Spending data were from the years 2004 to 2008 , and homicide rates, lagged 1 year, were from the years 2005 to 2009, the most recent 5-year period for which consistent data were available. Because the study uses publicly available, deidentified data, it was deemed exempt from review by the Institutional Review Board at Yale University School of Medicine.

\section{Measures}

Homicide rates

Homicide rates for each state were abstracted from the US Department of Justice Federal Bureau of Investigation's UCR (http://www.ucrdatatool.gov/Search/Crime/ State/StatebyState.cfm) and included the number of murders and non-negligent manslaughters per 100000 population. Rates excluded deaths caused by negligence, accidental deaths, attempts to kill and suicides.

\section{Social and public health services spending}

We calculated the total social and public health services spending per person living in poverty. Social services included primary, secondary and higher education; income supports (eg, cash assistance, general relief for low-income or needs-tests beneficiaries of public welfare programmes); transportation (eg, airports, waterways, vessels and public mass transit systems); environment (eg, sanitation and recreational programming and conservation of natural resources); public safety (eg, law enforcement and fire protection); and housing (eg, aid for public or private housing and community development). These data were obtained from the US Census Bureau Annual Survey of State and Local Government Finances (US Census Bureau, 2014), the Social Security Administration, Administration for Children and Families and the 
US Department of Agriculture. Public health spending was obtained from the US Census Bureau and included services such as expenditures for public health department activities, regulation for air and water quality and Special Supplemental Nutrition Program for Women Infants, and Children.

\section{Covariates}

We included several covariates based on previous literature. $^{8} 12131733$ We gathered data on several demographic and economic factors from the US Census Bureau, including percentages of the population under 18 years old and 65 years and older, percentage of female, percentage of white, percentage of Hispanic, percentage of adults aged 25 years or older with a high school diploma, percentage of population living in urban areas and percentage of individuals living below poverty. We gathered data on unemployment rates from the US Department of Labor and the percentage of children living in single-parent households from National KIDS COUNT (http://datacenter.kidscount.org). We obtained state-level GDP per capita from the US Department of Commerce and Bureau of Economic Analysis and Medicaid expenditure data from the National Health Expenditure Health Account data files maintained by the Centers for Medicare and Medicaid Services.

\section{Statistical analysis}

We first generated means and SD to describe variation across states for the year 2008. We then constructed unadjusted marginal models using repeated measures to test the linear effect of spending on homicide rates, accounting for both the effect of year and for clustering of SD at the state level. We then sought to build a multivariable model with covariates to adjust for potentially confounding variables. We first ran unadjusted models for all covariates and then explored multicollinearity among covariates that were significantly associated with homicide rates in our unadjusted analysis at $\mathrm{p}$ values $<0.10$. We included all potential covariates in linear regression models, stratified by year, to examine variance inflation factors (VIFs). We chose to exclude variables from our final multivariable model with VIF greater than 10 (ie, percentage of individuals living below poverty). We entered our remaining candidate variables into our marginal model and removed any non-significant variables $(\mathrm{p}>0.05)$ as long as they did not change current model estimates in order to derive the most parsimonious multivariable model.

Next, we tested whether the relationship between spending and homicide rates varied by percentages of individuals living in poverty. We first centred the spending variable around the mean for each year to reduce multicollinearity in the subsequent models. Next, we divided states into quartiles based on the percentages of individuals living in poverty and then calculated interaction terms by multiplying the dummy variables used to represent each quartile by our centred spending variable. Last, we entered the additional three interaction terms
Table 1 Sample descriptive characteristics (2008; $n=51$ states, including Washington, DC)

\begin{tabular}{ll}
\hline & M (SD) \\
\hline \% Under 18 years & $24.1(2.02)$ \\
\hline$\%$ Age 65+ years & $13.0(1.67)$ \\
\hline \% White & $80.3(13.53)$ \\
\hline$\%$ Hispanic & $10.1(9.72)$ \\
\hline \% Individuals with a high school diploma & $86.6(3.52)$ \\
\hline \% Children from single parent homes & $32.1(5.95)$ \\
\hline \% Urban & $72.2(15.28)$ \\
\hline \% Female & $50.7(0.80)$ \\
\hline Undividuals living below poverty & $12.8(2.98)$ \\
\hline Log (GDP/capita) & $5.3(1.27)$ \\
\hline Medicaid per \$100000 & $2.6(0.18)$ \\
\hline Total social service and public health & $62.1(80.99)$ \\
spending per individual living in poverty & $61.6(20.74)$ \\
\hline (\$1000) & \\
\hline Homicide rate per 100000 population, 2009 & $4.8(3.59)$ \\
\hline
\end{tabular}

GDP, gross domestic product.

$(k-1)$ and their corresponding main effects in our final adjusted model that included the centred spending variable. We explored the simple effects among each quartile in order to understand differential effects of spending. The simple effects for each poverty quartile were interpreted as the coefficient of the spending variable when that quartile was the reference category and thus equal to 0 in the interaction model. ${ }^{41}$

We modified our final model to test whether accounting for firearm ownership would alter our findings, as states with higher spending on social and public health services may also be those with more restrictive gun laws. Percentage of firearms owned per state was obtained from the Centers for Disease Control and Prevention's Behavioral Risk Factor Surveillance Survey ${ }^{42}{ }^{43}$; however, these data were only available within our study period for the year 2004. All models used spending rates and covariates lagged by 1 year to account for proposed time lag between spending and their effects on homicide rates. There were no missing data. All analyses were performed with SPSS V.23.0.

\section{RESULTS}

\section{State descriptive statistics}

On average, the spending on social and public health services was approximately $\$ 61627$ per individual living in poverty in 2008 (table 1), with estimates ranging from $\$ 30780$ to $\$ 128050$ per individual living in poverty. Homicide rates averaged 4.8 offences per 100000 population across all states in 2009, ranging from 0.8 to 24.2 offences per 100000 population. 


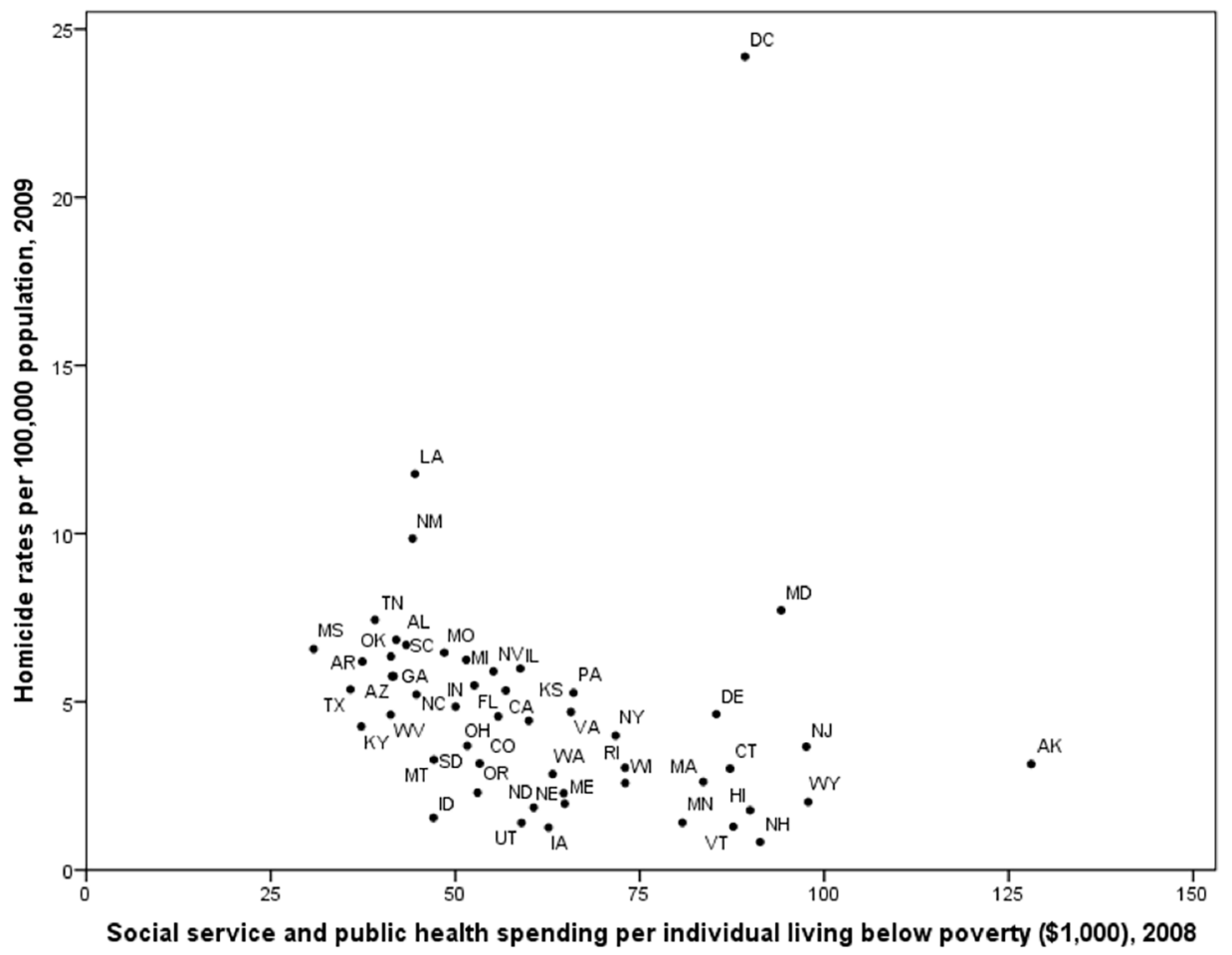

Figure 1 Association between 2008 spending rates on social and public health services and 2009 homicide rates in the USA.

\section{Association between spending and homicide rates}

In our unadjusted analysis, we found that spending on social and public health services was significantly associated with lower homicide rates (estimate $=-0.45$, $\mathrm{SE}=0.08, \mathrm{p}<0.001$; figure 1 ; table 2). After adjusting for potential confounders, including percentage of female, percentage of white, percentage of children living in single-parent homes and $\log$ (GDP per capita), we found that every $\$ 10000$ increase in spending per person living in poverty was associated with 0.87 fewer homicides per 100000 population (estimate $=-0.87$,
$\mathrm{SE}=0.15, \mathrm{p}<0.001)$ or a decrease of $16.4 \%$ of the overall average homicide rate across all states for the years 2005 through 2009 (5.3 offences/100 000 population). A decrease of approximately $16 \%$ of the estimated 16000 homicides that occur annually would result in approximately 2626 fewer deaths in the USA every year.

We also found significant interactions between spending and quartiles of percentages of individuals living in poverty to suggest that the effect of social service and public health spending on homicide rates may be moderated by the percentage of individuals

Table 2 Mixed effects models to determine the associations between social service and public health spending and homicide rates in the USA, 2005-2009†

\section{All states, including All states, excluding \\ DC ( $n=255)$ B (SE)}

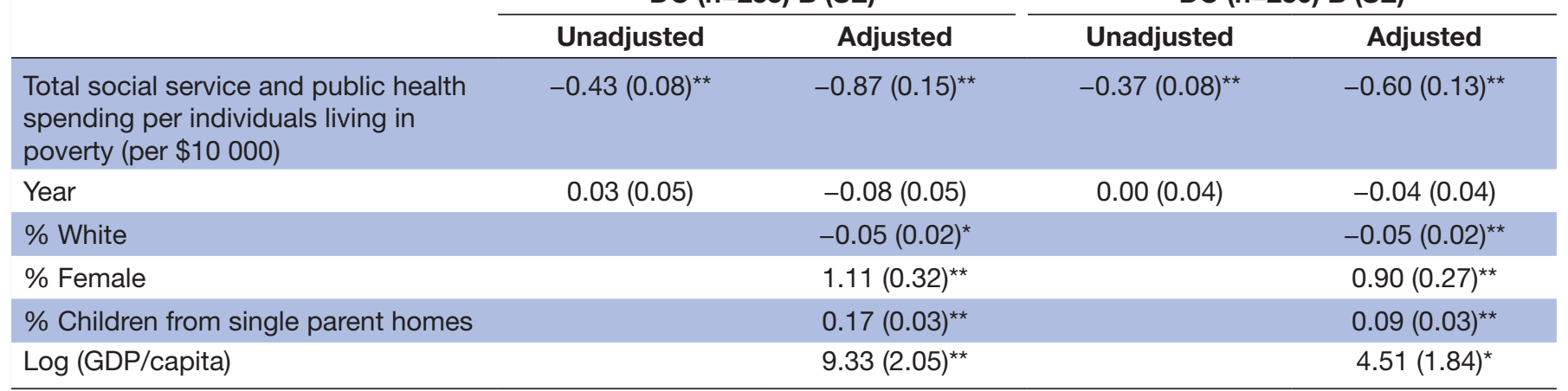

${ }^{*} \mathrm{p}<0.05 ;{ }^{* *} \mathrm{p}<0.01$.

†Includes a repeated statement indicating measures come from states over multiple years; spending data and all covariates are from the years 2004 to 2008, while homicide rates are from 2005 to 2009 in order to reflect a 1-year lag between spending and homicide.

GDP = gross domestic product 
Table 3 Simple effects of social and public health service spending on homicide rates in the USA, 2005-2009, for quartiles of individuals living in poverty from mixed effects models†

\begin{tabular}{ll}
\hline & B (SE) \\
\hline Quartile 1: 7.60\%-10.40\% & $-0.73(0.13)^{\star \star}$ \\
States: & \\
Alaska, Connecticut, Delaware, Hawaii, \\
Massachusetts, Maryland, Minnesota, New \\
Hampshire, New Jersey, Utah, Virginia, \\
Wisconsin, Wyoming \\
Quartile 2: 10.41\%-12.50\% \\
States: \\
Colorado, lowa, Illinois, Kansas, Maine, \\
North Dakota, Nebraska, Nevada, \\
Pennsylvania, Rhode Island, South Dakota, \\
Vermont, Washington \\
Quartile 3: 12.51\%-14.72\% \\
States: \\
Arizona, California, Florida, Georgia, Idaho, \\
Indiana, Michigan, Missouri \\
North Carolina, New York, Ohio, Oregon \\
Quartile 4: 14.73\%-21.19\% \\
States: \\
Alabama, Arkansas, Washington DC, \\
Kentucky, Louisiana, Mississippi, \\
Montana, New Mexico, Oklahoma, South \\
Carolina, Tennessee, Texas, \\
West Virginia \\
\hline ×osol
\end{tabular}

${ }^{*} \mathrm{p}<0.01$.

†Includes a repeated statement indicating measures come from states over multiple years; spending data and all covariates are from the years 2004 to 2008 , while homicide rates are from 2005 to 2009 in order to reflect a 1-year lag between spending and homicide.

$\ddagger$ Quartiles based on percentage of individuals living in poverty in 2008.

living in poverty (table 3 ). In the quartile of states with the highest percentages of individuals living in poverty, there was no significant effect of social service and public health spending on homicide rates; however, among the quartiles of states with lower percentages of individuals living in poverty, social service and public health spending had significant effects on homicide.

Additional analyses indicate that although percentage of firearm ownership was not associated with homicide in either our unadjusted model (estimate $=-0.019, \mathrm{SE}=0.025$, $\mathrm{p}=0.455$ ) or our adjusted model (estimate $=-0.019, \mathrm{SE}=0.021$, $\mathrm{p}=0.375$ ), it did appear to slightly diminish the association between social and public health service spending (estimate $=-0.51, \mathrm{SE}=0.260, \mathrm{p}=0.056)$ for the year $2004(\mathrm{n}=49)$. Furthermore, the adjusted association between social service and public health spending and homicide was consistent with our reported overall model (estimate $=-0.87, \mathrm{SE}=0.15$, $\mathrm{p}<0.001)$ when Washington, DC was excluded as an outlier (estimate $=-0.60, \mathrm{SE}=0.13, \mathrm{p}<0.001)$.

\section{DISCUSSION}

Results of this study indicate that states that invest more per person living in poverty in social and public health services have significantly lower homicide rates in the USA, with the exception of states with the highest percentages of individuals living in poverty. Although we cannot infer causality from this cross-sectional analysis, the magnitude of the effect was substantial. An added investment of $\$ 10000$ per person living in poverty was associated with more than 2600 homicides averted in a given year in the USA; however, future research is needed to determine approaches to efficiently and effectively allocate funds among social and public health services to reduce violence in the USA. Based on the conservative estimates that each homicide costs of approximately $\$ 1.5$ million, ${ }^{3}$ appropriate investments in social and public health services may be linked to substantial cost savings. Our results echo several international studies that show that countries that spend more in various forms of welfare support have reduced homicide rates, ${ }^{33} 44$ although one study of international comparisons did not show such an association. ${ }^{17}$ Our study expands this literature by examining state-level spending effects across the US, suggesting the need to further investigate potential policy levers that may mitigate the devastating and costly rates of homicide in the USA.

In our study, we also find that the effect of social service and public health spending on reduced homicide rates is most prominent among states with less poverty, perhaps where additional resources, such as community-based crime reduction efforts, are available to mitigate crime. We hypothesise that in states with very high poverty rates, social service and public health spending may be insufficient in the absence of other targeted community interventions such as Baltimore's 'Safe Streets', 'Ceasefire Illinois' or other similar efforts. Furthermore, social and public health service spending may buffer the impact of poverty on homicide. ${ }^{1345}$ The intricacies of this relationship, however, are beyond the scope of this paper.

Our findings should be interpreted in light of some important limitations. First, this analysis was limited to 5 years of data, thus preventing the ability to examine longer term effects. Furthermore, as these findings are based on homicide data from the years 2005 and 2009, they may not be generalisable to more current homicide rates. Additionally, we lacked complete data on potentially important confounders, such as percentage of firearm owners and proportion of female-headed households, which limited our ability to account for this variation across states. We do believe, however, that the proportion of female-headed households is likely similar to the percentage of children living in single-parent homes, which we were able to take into account. Last, because the subcomponents of total social service and public health spending are highly correlated in our sample, we were unable to determine the independent effects of each service (eg, housing, education and public health) on homicide rates and thus are unable to make specific policy recommendations. Given their strong correlation 
within states, different study designs may be needed to isolate their independent effects. Additional research is needed to determine efficient and effective allocation of funds towards social and public health services in order to improve national health outcomes.

In conclusion, based on our findings, spending on social services and public health initiatives appears to be associated with significantly lower homicide rates and thus may provide promising avenues for homicide reduction in the USA, particularly among states with lower levels of poverty. Despite the limitations of this analysis, results suggest continued investment in social determinants of health ${ }^{46}$ can have important impacts on health and health behaviours, including violence.

Contributors HLS, MEC, KMT-S, LT and EHB conceptualised the design of the study. MEC and ER gathered the data. HLS and MEC conducted the analyses, and HLS wrote the first draft. All authors contributed to the interpretation of results, revising the paper and approve the final version for submission.

Funding This work was funded by grants from the Robert Wood Johnson Foundation (grant \#71531) and Blue Cross Blue Shield of Massachusetts Foundation, Inc.

\section{Competing interests None declared.}

Provenance and peer review Not commissioned; externally peer reviewed.

Data sharing statement Data are publicly available; for more details or questions about the analytic dataset, please contact the corresponding author.

Open Access This is an Open Access article distributed in accordance with the Creative Commons Attribution Non Commercial (CC BY-NC 4.0) license, which permits others to distribute, remix, adapt, build upon this work non-commercially, and license their derivative works on different terms, provided the original work is properly cited and the use is non-commercial. See: http://creativecommons.org/ licenses/by-nc/4.0/

(c) Article author(s) (or their employer(s) unless otherwise stated in the text of the article) 2017. All rights reserved. No commercial use is permitted unless otherwise expressly granted.

\section{REFERENCES}

1. Sumner SA, Mercy JA, Dahlberg LL, et al. Violence in the United States: Status, challenges, and opportunities. JAMA 2015;314:478-88.

2. Xu J, Murphy S, Kochanek K, et al. Deaths: Final data for 2013. National Vital Statistics Report 2016;64:1-119.

3. Centers for Disease Control and Prevention, National Center for Injury Prevention and Control. Fatal Injuries, Both Sexes, All Ages, United States. 2010: Centers for Disease Control and Prevention. 2014. https://wisqars.cdc.gov:8443/costT/cost_Part1_Finished.jsp (accessed Aug 30 2016).

4. DeLisi M, Kosloski A, Sween M, et al. Murder by numbers: monetary costs imposed by a sample of homicide offenders. J Forens Psychiatry Psychol 2010;21:501-13.

5. Redmond L. Surviving: When Someone You Love Was Murdered: a Professional's Guide to Group Grief Therapy for Families \& Friends of Murder Victims. Clearwater, FL: Psychological Consultation and Education Services, 1989.

6. Grinshteyn E, Hemenway D. Violent death rates: the US compared with other high-income OECD countries, 2010. Am J Med 2016;129:266-73.

7. Rockett IR, Regier MD, Kapusta ND, et al. Leading causes of unintentional and intentional injury mortality: United States, 20002009. Am J Public Health 2012;102:e84-e92.

8. Walker GN, McLone S, Mason M, et al. Rates of firearm homicide by Chicago region, age, sex, and race/ethnicity, 2005-2010. J Trauma Acute Care Surg 2016;81:S48-53.

9. Price JH, Thompson AJ, Dake JA. Factors associated with state variations in homicide, suicide, and unintentional firearm deaths. $J$ Community Health 2004;29:271-83.
10. Beard JH, Morrison CN, Jacoby SF, et al. Quantifying disparities in Urban firearm violence by race and place in Philadelphia, Pennsylvania: A cartographic Study. Am J Public Health 2017;107:371-3.

11. Pridemore WA. What we know about social structure and homicide: a review of the theoretical and empirical literature. Violence Vict 2002;17:127-56.

12. Pridemore WA. Poverty matters: a reassessment of the inequalityhomicide relationship in cross-National Studies. Br J Criminol 2011;51:739-72.

13. Rogers ML, Pridemore WA. The effect of poverty and social protection on national homicide rates: Direct and moderating effects. Soc Sci Res 2013;42:584-95.

14. McCall PL, Land KC, Parker KF. Heterogeneity in the rise and decline of city-level homicide rates, 1976-2005: A latent trajectory analysis. Soc Sci Res 2011;40:363-78.

15. Fleegler EW, Lee LK, Monuteaux MC, et al. Firearm legislation and firearm-related fatalities in the United States. JAMA Intern Med 2013;173:732-40.

16. Loftin $C$, McDowall $D$, Wiersema $B$, et al. Effects of restrictive licensing of handguns on homicide and suicide in the District of Columbia. N Engl J Med 1991;325:1615-20.

17. Elgar FJ, Aitken N. Income inequality, trust and homicide in 33 countries. Eur J Public Health 2011;21:241-6.

18. Galea S, Karpati A, Kennedy B. Social capital and violence in the United States, 1974-1993. Soc Sci Med 2002;55:1373-83.

19. Wilson M, Daly M. Life expectancy, economic inequality, homicide, and reproductive timing in Chicago neighbourhoods. BMJ 1997;314:1271-4.

20. Casas A, Duell J, O'Malley T, et al. Housing Relocation Policy and Violence: A Literature Review. Trauma Violence Abuse 2016;17.

21. Reynolds AJ, Temple JA, Robertson DL, et al. Long-term effects of an early childhood intervention on educational achievement and juvenile arrest: A 15-year follow-up of low-income children in public schools. JAMA 2001;285:2339-46.

22. Culyba AJ, Jacoby SF, Richmond TS, et al. Modifiable neighborhood features associated with adolescent homicide. JAMA Pediatr 2016;170:473-80.

23. Bradley E, Canavan M, Rogan E, et al. Variations in health outcomes across the United States: The roles of social service, public health, and health care spending. Health Affairs 2016;35:760-8.

24. Taylor LA, Tan AX, Coyle CE, et al. Leveraging the social determinants of health: what works? PLoS One 2016;11:e0160217.

25. Worrall JL. Social support and homicide. Homicide Stud 2009;13:124-43.

26. Messner SF. Graphic mobility, governmental assistance to the poor, and rates of urban crime. J Crime Justice 1986:9:1-18.

27. Hannon L. AFDC and homicide. J Sociol Soc 1997;24:125-36.

28. DeFronzo J. Economic assistance to impoverished Americans. Criminology 1983;21:119-36.

29. Chamlin M, Cochran J, Lowenkamp C. A longitudinal analysis of the welfare-homicide relationship: testing two (nonreductionist) macrolevel theories. Homicide Studies 2002;6:39-60.

30. Market CE. crime and community: toward a mid-range theory of post industrial violence. Theoretical Criminology 1997;1:147-72.

31. Sampson RJ. Urban Black Violence: the effect of male joblessness and family disruption. Am J Sociol 1987;93:348-82.

32. Savage J, Bennett R, Danner M. Economic assistance and crime: a cross-national investigation. Eur J Criminol 2008;5:217-38.

33. McCall PL, Brauer JR. Social welfare support and homicide: longitudinal analyses of European countries from 1994 to 2010. Soc Sci Res 2014:48:90-107.

34. Wenglinsky $\mathrm{H}$. Finance equalization and within-school equity: the relationship between education spending and the social distribution of achievement. Educ Eval Policy Anal 1998;20:269-83.

35. Condron DJ, Roscigno VJ. Disparities within: Unequal spending and achievement in an Urban school district. Sociol Educ 2003;76:18-36.

36. Carpiano RM. Neighborhood social capital and adult health: an empirical test of a Bourdieu-based model. Health Place 2007;13:639-55.

37. Sampson RJ, Morenoff JD, Earls F. Beyond social capital: Spatial dynamics of collective efficacy for children. Am Sociol Rev 1999;64:633-60.

38. McLaughlin KA, Green JG, Alegría M, et al. Food insecurity and mental disorders in a national sample of U.S. Adolescents. Child Adolesc Psychiatry Ment Health 2012;51:1293-303.

39. Alaimo K, Olson CM, Frongillo EA. Food insufficiency and American school-aged children's cognitive, academic, and psychosocial development. Pediatrics 2001;108:44-53.

40. Viner RM, Ozer EM, Denny S, et al. Adolescence and the social determinants of health. The Lancet 2012;379:1641-52. 
41. Dawson JF. Moderation in managemenet research: what, why, when, and How. J Bus Psychol 2014;29:1-19.

42. Centers for Disease Control and Prevention. Behavioral Risk Factor Surveillance System: BRFSS 2004 Survey Data. 2014. https://www.cdc. gov/brfss/annual_data/annual_2004.htm (accessed June 12 2017).

43. Monuteaux MC, Lee LK, Hemenway D, et al. Firearm ownership and violent crime in the U.S.: An Ecologic Study. Am J Prev Med 2015;49:207-14.
44. Rubin J, Taylor J, Krapels J, et al. Corporation R, ed. Are better health outcomes related to social expenditure? A cross-national empirical analysis of social expenditure and population health measures. Santa Monica, CA, 2016.

45. Inequality SJ. welfare state, and homicide: further support for the institutional anomie thoery. Criminology 2000;38:1021-42.

46. Marmot M. Social determinants of health inequalities. Lancet 2005;365:1099-104. 